\title{
An engineered fatty acid synthase combined with a carboxylic acid reductase enables de novo production of 1-octanol in Saccharomyces cerevisiae
}

\author{
Sandra Henritzi ${ }^{1}$, Manuel Fischer ${ }^{2}$, Martin Grininger ${ }^{2}$, Mislav Oreb ${ }^{1}$ and Eckhard Boles ${ }^{1 *}$
}

\begin{abstract}
Background: The ideal biofuel should not only be a regenerative fuel from renewable feedstocks, but should also be compatible with the existing fuel distribution infrastructure and with normal car engines. As the so-called drop-in biofuel, the fatty alcohol 1-octanol has been described as a valuable substitute for diesel and jet fuels and has already been produced fermentatively from sugars in small amounts with engineered bacteria via reduction of thioesterasemediated premature release of octanoic acid from fatty acid synthase or via a reversal of the $\beta$-oxidation pathway.

Results: The previously engineered short-chain acyl-CoA producing yeast Fas $1^{\mathrm{R} 1834 \mathrm{~K}} / \mathrm{Fas} 2$ fatty acid synthase variant was expressed together with carboxylic acid reductase from Mycobacterium marinum and phosphopantetheinyl transferase Sfp from Bacillus subtilis in a Saccharomyces cerevisiae $\Delta$ fas $1 \Delta$ fas $2 \Delta f a a 2$ mutant strain. With the involvement of endogenous thioesterases, alcohol dehydrogenases, and aldehyde reductases, the synthesized octanoylCoA was converted to 1 -octanol up to a titer of $26.0 \mathrm{mg} \mathrm{L}^{-1}$ in a $72-\mathrm{h}$ fermentation. The additional accumulation of $90 \mathrm{mg} \mathrm{L}^{-1}$ octanoic acid in the medium indicated a bottleneck in 1-octanol production. When octanoic acid was supplied externally to the yeast cells, it could be efficiently converted to 1-octanol indicating that re-uptake of octanoic acid across the plasma membrane is not limiting. Additional overexpression of aldehyde reductase Ahr from Escherichia coli nearly completely prevented accumulation of octanoic acid and increased 1-octanol titers up to $49.5 \mathrm{mg} \mathrm{L}^{-1}$. However, in growth tests concentrations even lower than $50.0 \mathrm{mg} \mathrm{L}^{-1}$ turned out to be inhibitory to yeast growth. In situ extraction in a two-phase fermentation with dodecane as second phase did not improve growth, indicating that 1-octanol acts inhibitive before secretion. Furthermore, 1-octanol production was even reduced, which results from extraction of the intermediate octanoic acid to the organic phase, preventing its re-uptake.
\end{abstract}

Conclusions: By providing chain length control via an engineered octanoyl-CoA producing fatty acid synthase, we were able to specifically produce 1-octanol with S. cerevisiae. Before metabolic engineering can be used to further increase product titers and yields, strategies must be developed that cope with the toxic effects of 1-octanol on the yeast cells.

Keywords: Fatty alcohol, 1-octanol, Carboxylic acid reductase, Biofuel, Octanoic acid, Caprylic acid, Fatty acid synthase, Short-chain fatty acids, Yeast, Saccharomyces cerevisiae

\footnotetext{
*Correspondence: e.boles@bio.uni-frankfurt.de

${ }^{1}$ Faculty of Biological Sciences, Institute of Molecular Bioscience, Goethe

University Frankfurt, Max-von-Laue-Str. 9, 60438 Frankfurt, Germany

Full list of author information is available at the end of the article
} 


\section{Background}

Dwindling fossil resources and a growing global energy demand, especially in the sector of human mobility and transportation, are leading to economic and environmental burdens. This development poses a serious threat for the environment with respect to emissions of greenhouse gases and particulate matter from traditional fuels like gasoline and diesel [1,2]. An alternative is the development of sustainable and regenerative fuels from renewable feedstocks. However, those substitutes are not always compatible with the existing infrastructure for distribution or with traditional vehicle engines [3], but may require technical modifications of engines due to different physicochemical properties and combustion behaviors. Therefore, current research focuses on the application of so-called drop-in biofuels. They are considered as complete replacements of fossil fuels or as additives for blending due to similar characteristics regarding critical parameters $[4,5]$. Among a comprehensive portfolio of approved molecules from microbial production
[5-9], 1-octanol has acquired special attention as substitute for diesel and jet fuels [10-13]. Previous studies [10, 14] compared various characteristics of fossil-derived as well as bio-derived diesel fuels with saturated shortand medium-chain alcohols, and showed that 1-octanol exhibits best matching overall properties compared to ethanol or other long-chain alcohols.

Various approaches are under investigation for the microbial synthesis of higher unbranched alcohols with respect to the origin of the saturated carbon chain and the formation of the terminal hydroxyl group. They are based to some extent on entirely different metabolic pathways in bacterial as well as yeast systems (Fig. 1). Most approaches aim at harvesting acyl chain for the synthesis of the higher alcohol. Two major biochemical strategies can be distinguished for the acyl chain synthesis: (1) The alpha-ketoacid route [15] exerts the recursive elongation of alpha-ketoacids by one carbon atom with an adapted leucine biosynthesis pathway and gives access to saturated carbon chains from $C_{3}$ to $C_{9}$ [16]. (2) Fatty acid

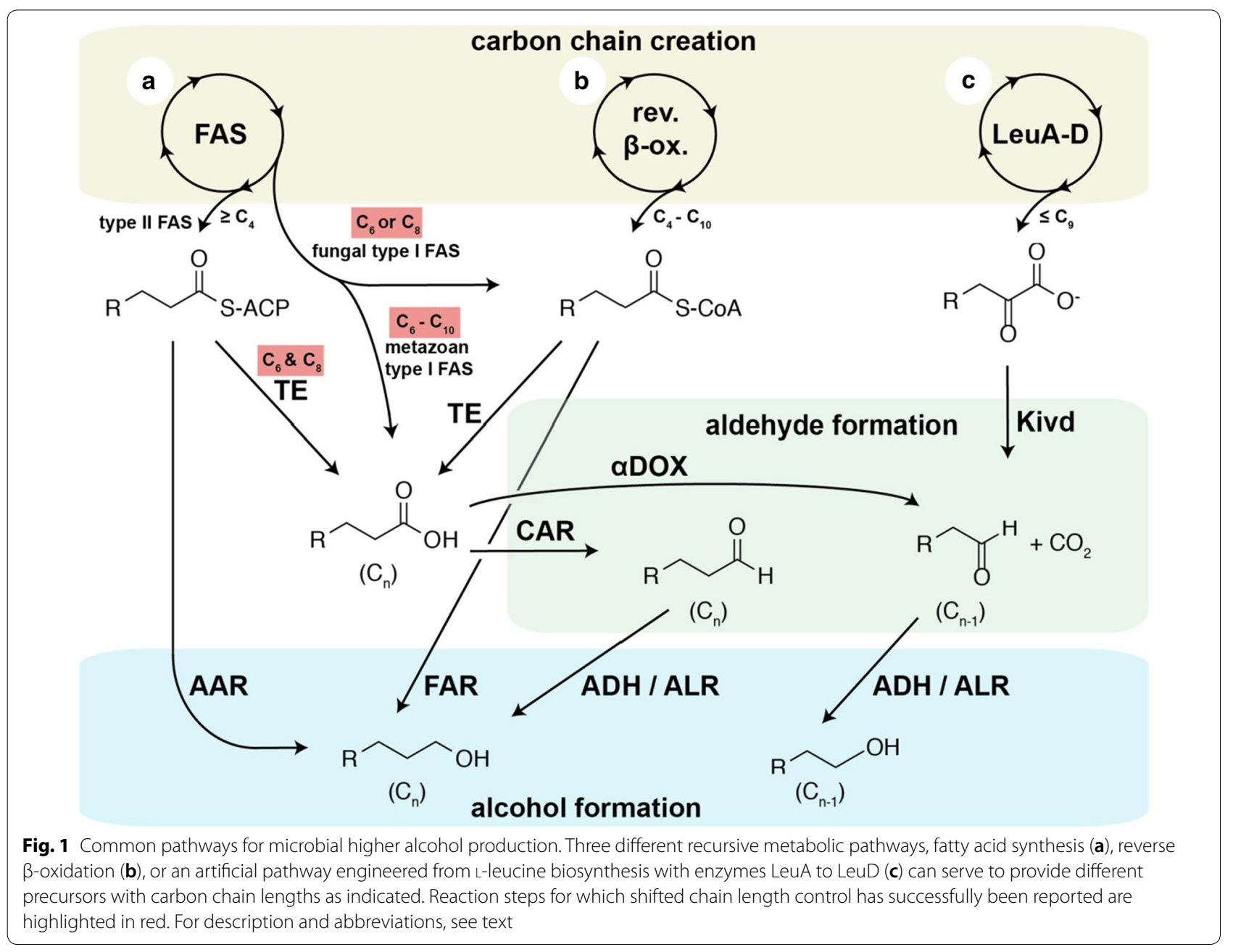


synthesis or an artificially induced reverse $\beta$-oxidation $[17,18]$ exerts two-carbon elongation of beta-ketoacids for saturated acyl chain creation.

In all these cases, the desired alcohol must be formed in a final reaction step via reduction of a corresponding precursor, either CoA-thioester, ACP-tethered thioester, or free carboxylate. Fatty acyl-CoA reductases (FAR) and acyl-ACP reductases (AAR) proved to be suitable for the reduction of both thioester species, which they directly reduce to the corresponding alcohol [17, 19-26] and often do not discriminate between ACP and $\mathrm{CoA}$ as carrier [27]. A free carboxylate is comparably unreactive, but can be efficiently converted to a $C_{n-1}$ aldehyde by $\alpha$-dioxygenases ( $\alpha \mathrm{DOX}$ ) under decarboxylative elimination of the terminal carboxyl group [28] or to a $C_{n}$ aldehyde by carboxylic acid reductases (CAR) [29-31]. The CAR-enzyme family requires a phosphopantetheinylation by a phosphopantetheinyl transferase to be active [32]. The aldehydes can be further reduced to alcohols by various aldehyde reductases (ALR) or alcohol dehydrogenases (ADH) [6, 33]. A broad applicability of all these reducing enzymes is facilitated by a promiscuous substrate acceptance of FARs/AARs [19, 20, 23, 34, 35] as well as CAR [31, 36, 37] and ALR/ADH [30]. In aiming for microbial short/medium-chain alcohol production, the bottleneck does therefore rather lie in the supply of the respective short/medium-chain acyl chain than the downstream reducing enzymes. This is reflected in the variety of publications about fatty alcohol production derived from the naturally defined pool of fatty acids in the $C_{16} / C_{18}$-range $[23,25,38]$, while work on short/medium-chain alcohol production is rare. Marcheschi et al. [39] reported the production of mixed $\mathrm{C}_{3}-\mathrm{C}_{8}$-alcohols with the $\alpha$-ketoacid route using mutated LeuA variants in E. coli, but with a maximal 1-octanol yield of $15 \mathrm{mg} \mathrm{L}^{-1}$, which accounts for only $0.1 \%$ in this mixture. Higher titers were reported using a reverse $\beta$-oxidation route and an aldehyde/alcohol dehydrogenase AdhE2 from Clostridium acetobutylicum for reducing the obtained CoA-ester to give $65 \mathrm{mg} \mathrm{L}^{-1} 1$-octanol as one component of a $\mathrm{C}_{2}-\mathrm{C}_{10}$ alcohol mixture in $\mathrm{E}$. coli [40] or even $100 \mathrm{mg} \mathrm{L}^{-1}$ as minor product after further metabolic optimizations [18]. For the direct usage of fatty acyl-CoAs as precursors, Sheng et al. [41] reported an elaborate strategy to escape from the normal product spectrum of mainly $\mathrm{C}_{16} / \mathrm{C}_{18}$. They directed a fatty acylCoA reductase to the peroxisome to capture mediumchain substrates from $\beta$-oxidation, which resulted in the production of $1 \mathrm{~g} \mathrm{~L}^{-1} \mathrm{C} 10, \mathrm{C}_{12}$ and $\mathrm{C}_{16}$ fatty alcohols in $S$. cerevisiae [41]. In spite of the success of producing short/medium-chain alcohols, these examples illustrate the difficulty of chain length control that causes dissipation of synthetic capacity and finally requires separation of the desired 1-octanol from product mixtures later on. Akhtar et al. [14] were first in publishing the introduction of a thioesterase, Tes3 from Anaerococcus tetradius, in a CAR/Ahr-expressing E. coli, which is highly specific for $\mathrm{C}_{6}$ - and $\mathrm{C}_{8}$-acyl thioesters. In this way, they harvested immature fatty acyl-ACPs from the bacterial fatty acid biosynthesis and obtained up to $62 \mathrm{mg} \mathrm{L}^{-1} 1$-octanol besides $29 \mathrm{mg} \mathrm{L}^{-1} 1$-hexanol with laboratory E. coli BL21 cells [14].

Yeast as the applied organism offers certain advantages over the hitherto exclusively reported $E$. coli systems for microbial 1-octanol production. S. cerevisiae is highly robust, shows a high tolerance to stress in fermentative processes, and ferments sugars at low $\mathrm{pH}$ values $[42,43]$. Also, many genetic manipulation tools are established which make yeast a very attractive organism for metabolic engineering [44]. Several studies have been dealing with the overproduction of long-chain fatty acids and derivatives in S. cerevisiae [24-26, 30, 45].

Due to the spatial encapsulation of fatty acid synthesis in fungi in a barrel-shaped multienzyme complex [46-50], the strategy of hydrolyzing short/medium-chain acyl-ACP with specific thioesterases, as e.g., Tes3, is difficult to apply for this system. In previous studies, this was addressed by introducing a structurally different metazoan fatty acid synthase with fused thioesterase [51] or the incorporation of a thioesterase in the fungal fatty acid synthase's reaction chamber [52]. We have recently reported the rational engineering of the type I fatty acid synthase (FAS) from $S$. cerevisiae for the selective production of short/medium-chain fatty acids $\left(C_{6}\right.$ or $\left.C_{8}\right)$ [53] based on a preceding in vitro/in silico approach [54]. Mutations in the selected enzymatic domains, controlling fatty acid chain length, led to a total yield of $245 \mathrm{mg} \mathrm{L}^{-1}$ $\left(\mathrm{C}_{6}\right.$ or $\mathrm{C}_{8}$ fatty acid) and a specificity for $\mathrm{C}_{8}$ fatty acids of $90 \%$ (of secreted fatty acids), resembling to date the most efficient and most specific short/medium-chain fatty acids producing yeast strains $[51,52,55,56]$. We consider this strain as ideal platform to produce 1-octanol. Here, we show that combining an octanoyl-CoA producing engineered FAS from yeast with heterologously expressed carboxylic acid reductases and aldehyde reductases, together with endogenous thioesterases and alcohol dehydrogenases, enables efficient de novo production of 1-octanol from glucose with S. cerevisiae.

\section{Results and discussion}

\section{Biosynthesis of 1-octanol from glucose}

In this study, we engineered a synthetic pathway to produce 1-octanol from glucose in $S$. cerevisiae in which the chain length of the fatty alcohol is determined by the product release of a mutated yeast FAS, namely Fas1 ${ }^{\text {R1834K }} /$ Fas2 [53]. Host strain RPY21 which exhibits 
deletions of both $F A S$ genes, FAS1 and FAS2, as well as the gene $F A A 2$ encoding a short/medium-chain fatty acyl-CoA synthetase, was transformed with centromeric vectors expressing $F A S 1^{R 1834 K}$ and $F A S 2$ under control of their native promoters. We had previously reported that the $\mathrm{FAS}^{\mathrm{R} 1834 \mathrm{~K}}$ mutant version of FAS in concert with the thioesterase activities of three short-chain acylCoA:ethanol acyltransferases, Eht1, Eeb1, and Mgl2, produces high amounts of octanoic acid [53]. To avoid subsequent degradation of octanoic acid, we additionally deleted $F A A 2$ which is required for the re-activation of octanoic acid to octanoyl-CoA initiating its degradation by $\beta$-oxidation [57]. Interestingly, it has been reported before that the deletion of FAA2 already in a wild-type FAS background leads to the production of low amounts of octanoic acid [58]. In the $\mathrm{FAS}^{\mathrm{R} 1834 \mathrm{~K}}$ mutant background, the deletion of $F A A 2$ resulted in an increase of up to $25 \%$ in octanoic acid production $\left(301 \mathrm{mg} \mathrm{L}^{-1}\right.$; data not shown). To produce 1-octanol from free octanoic acid, we overexpressed a heterologous carboxylic acid reductase (CAR) from Mycobacterium marinum under the control of the strong and constitutive $H X T 7^{-1-392}$ promotor fragment together with the phosphopantetheinyl transferase Sfp from Bacillus subtilis under the control of the strong PGK1 promoter on a multicopy vector in RPY21 expressing Fas1 $1^{\mathrm{R} 1834 \mathrm{~K}} / \mathrm{Fas} 2$ [14]. CAR uses NADPH and ATP in order to reduce free fatty acids to the corresponding aldehydes [31] (Fig. 2) and must be activated by a phosphopantetheine transferase: in this study, Sfp, which attaches the prosthetic group 4'-phosphopantetheine to the enzyme [31, 32]. The aldehydes can be further reduced to primary alcohols by endogenous alcohol dehydrogenases $(\mathrm{ADH})$ or aldehyde reductases (ALR) in yeast $[29,33]$.

Cultivation of the yeast cells in potassium phosphate buffered medium at $\mathrm{pH} 6.5$ with $2 \%$ glucose under aerobic conditions resulted in the accumulation of 1-octanol in the extracellular medium with titers of up to $26.0 \pm 3.6 \mathrm{mg} \mathrm{L}^{-1}\left(2.8 \pm 0.3 \mathrm{mg} \mathrm{L}^{-1} \mathrm{OD}_{600}^{-1}\right)$ after $72 \mathrm{~h}$ (Fig. 3a), which was also indicated by a strong specific smell of the cell cultures. The production of 1-octanol confirmed that $S$. cerevisiae contains suitable endogenous ADHs/ALRs for the reduction of 1-octanal (Fig. 2) as shown earlier [29]. Besides 1-octanol, also small amounts of 1-hexanol (5.5 $\pm 0.6 \mathrm{mg} \mathrm{L}^{-1}$ after $72 \mathrm{~h}$; data not shown) could be determined. This was expected since FAS ${ }^{\mathrm{R} 1834 \mathrm{~K}}$ also produces small amounts of hexanoic acid which is then also reduced by CAR to its corresponding aldehyde $[14,31,53]$. In contrast, although decanoic acid was another side product of FAS ${ }^{\mathrm{R} 1834 \mathrm{~K}}[53]$, decanol was not detected.

It is worthy to mention that even the control strain RPY21, expressing wild-type FAS and overexpressing CAR and Sfp, secreted 1-octanol in small amounts $\left(3.9 \pm 0.1 \mathrm{mg} \mathrm{L}^{-1}\right)$ (Fig. 3a), which has also been reported before in a comparable setup [29]. Possibly, this is the result of the small amounts of octanoic acid produced by wild-type FAS or the mitochondrial type II FAS system in S. cerevisiae $[53,54,59]$, especially together with deletion of FAA2 as in strain RPY21 [58].

To determine the limiting factors in 1-octanol production in strain RPY21/FAS ${ }^{\mathrm{R} 1834 \mathrm{~K}}$ overexpressing CAR and $\mathrm{Sfp}$, we furthermore analyzed the accumulation of free octanoic acid in the culture medium, and detected a considerable titer of $90.3 \pm 6.8 \mathrm{mg} \mathrm{L}^{-1}$ after $72 \mathrm{~h}$ (Fig. 3c). Compared to the same strain without CAR which accumulated $118.9 \pm 7.3 \mathrm{mg} \mathrm{L}^{-1}$ octanoic acid, this reveals that $76 \%$ of precursor substrate remained unused for octanol production, suggesting a bottleneck either in the CAR or the ADH/ALR reactions, or losses due to secretion of octanoic acid out of the cells.

The decreased maximal optical density after $72 \mathrm{~h}$ of the yeast culture RPY21/FAS ${ }^{\mathrm{R} 1834 \mathrm{~K}}$ overexpressing CAR and Sfp indicated that 1-octanol or the other pathway intermediates octanoic acid and octanal might have a toxic effect on the yeast cells and inhibit their growth

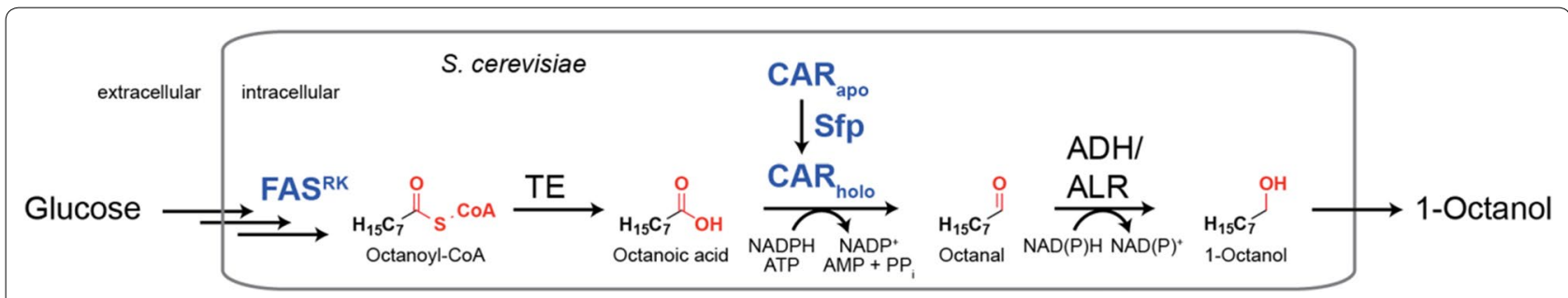

Fig. 2 Metabolic pathway for 1-octanol production in S. cerevisiae from glucose via fatty acid biosynthesis. A mutant version of S. cerevisiae FAS

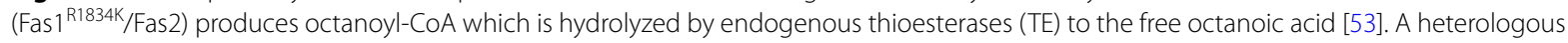
carboxylic acid reductase (CAR) from M. marinum then converts the free fatty acid to octanal which is further reduced to 1-octanol by endogenous alcohol dehydrogenases (ADH) and aldehyde reductases (ALR) [29]. CAR must be activated by the phosphopantetheinyl tranferase Sfp from Bacillus subtilis [31]. Heterologous or mutated enzymes are marked in blue. FAS ${ }^{\text {RK }}$ means FAS ${ }^{\text {R1834K }}$ 

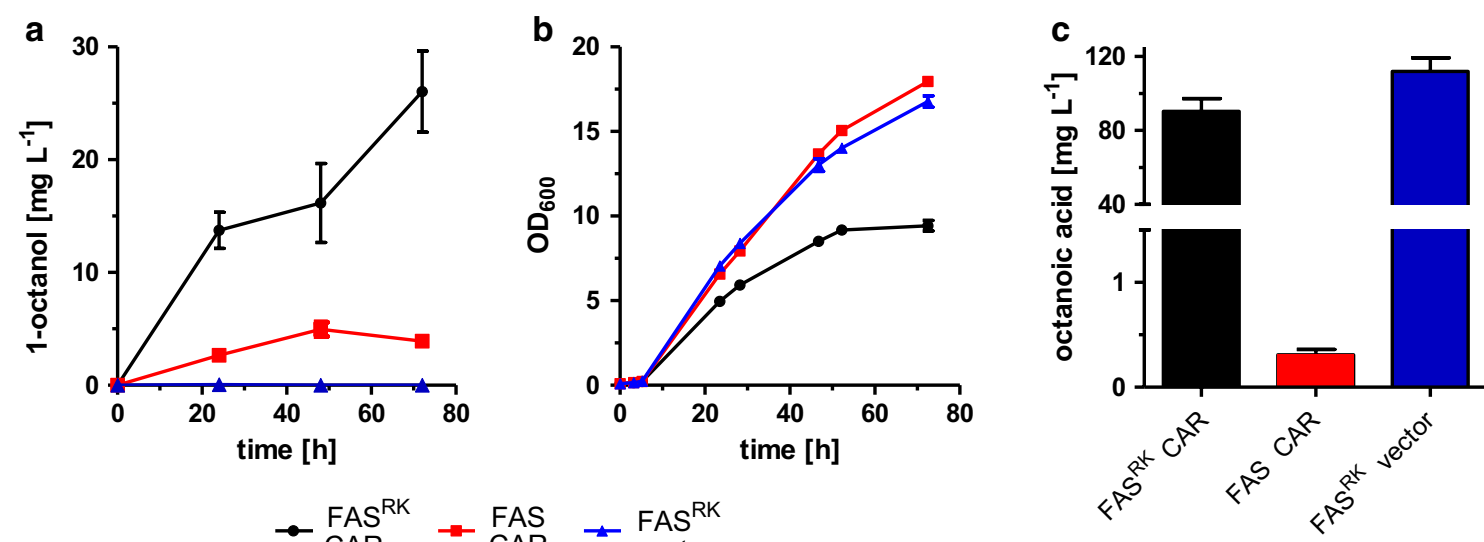

Fig. 3 Production of 1-octanol with S. cerevisiae. Strain RPY21 expressing mutated FASR1834K as well as CAR and Sfp from a high-copy plasmid (black), was grown for $72 \mathrm{~h}$ in buffered YPD medium. For reference, analogous combinations of wild-type FAS, CAR, and Sfp (red) as well as mutated FAS ${ }^{R 1834 K}$ with empty vector instead of CAR and Sfp are shown (blue). Error bars reflect the standard deviations from three biological replicates. $\mathrm{OD}_{600}(\mathbf{a})$ and extracellular 1-octanol concentrations $(\mathbf{b})$ were analyzed at different time points. $\mathbf{c}$ Final octanoic acid concentration in the extracellular culture medium after $72 \mathrm{~h}$. FAS ${ }^{\mathrm{RK}}$ means $\mathrm{FAS}^{\mathrm{R} 1834 \mathrm{~K}}$

(Fig. 3b). To test the inhibitory effects, different concentrations of 1-octanol, octanal, and octanoic acid were added to yeast cultures of the wild-type strain BY4741 and growth curves were determined (Fig. 4). Indeed, at the lowest tested concentration of $50 \mathrm{mg} \mathrm{L}^{-1}$ of 1-octanol or octanal in the culture medium, slightly inhibited growth of the yeast cells was observed, and growth was completely prevented at a concentration of $150 \mathrm{mg} \mathrm{L}^{-1}$ (Fig. 4a, b). In contrast, octanoic acid is less toxic, and moderate cell growth was even observed at a concentration of $400 \mathrm{mg} \mathrm{L}^{-1}$ (Fig. 4c).

\section{Re-uptake of secreted octanoic acid from the medium}

To rule out that the secretion of octanoic acid into the culture medium is a limiting factor for 1-octanol production, we analyzed the transport of octanoic acid back into the cell and its further conversion to 1-octanol by overexpressing CAR and Sfp in the wild-type strain BY4741 in buffered media supplemented with $90 \mathrm{mg} \mathrm{L}^{-1}$ octanoic acid. After $24 \mathrm{~h}, 11.0 \pm 0.8 \mathrm{mg} \mathrm{L}^{-1} 1$-octanol was detected (Fig. 5a), showing that octanoic acid can be transported back into the cell and subsequently be reduced by CAR together with ADHs/ALRs to 1-octanol. Nevertheless, the concentration of octanoic acid in the medium also
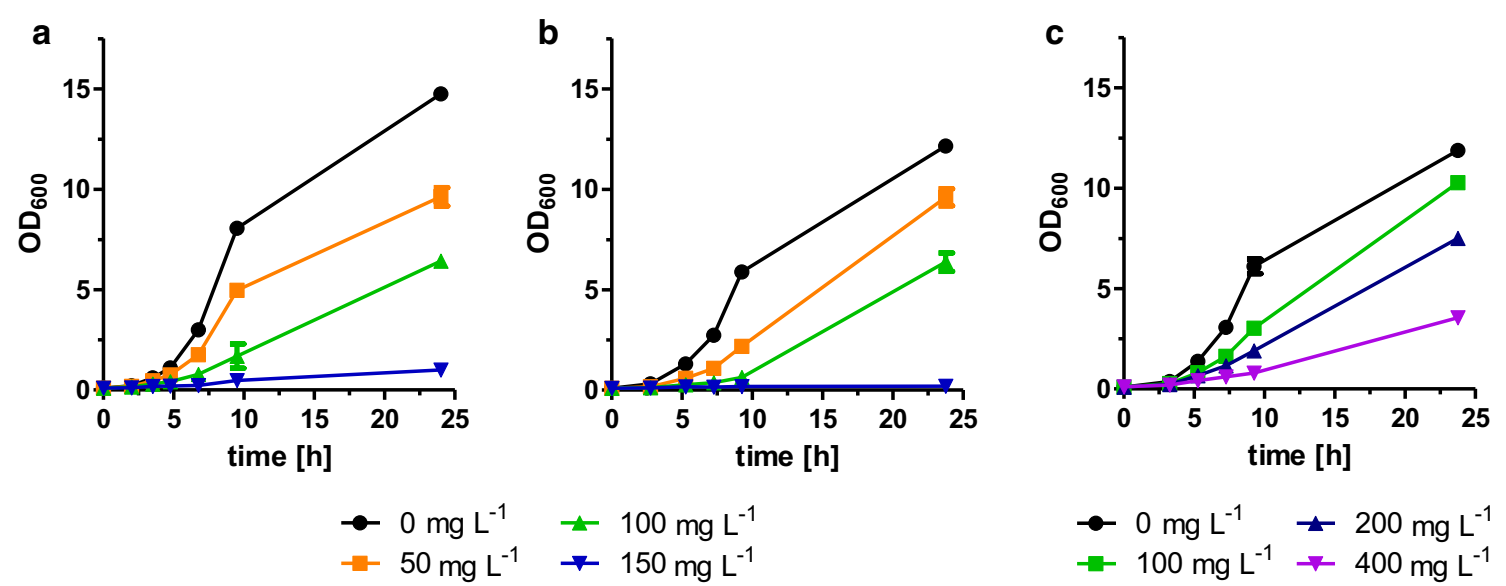

Fig. 4 Inhibitory effects of 1-octanol, octanal, and octanoic acid added to the culture medium of strain BY4741. The yeast strain BY4741 was cultivated for $24 \mathrm{~h}$ in buffered YPD medium supplemented with different concentrations of $\mathbf{a} 1$-octanol $\mathbf{b}$ octanal, or c octanoic acid. Error bars reflect the standard deviations from two biological replicates. $\mathrm{OD}_{600}$ was analyzed at different time points 

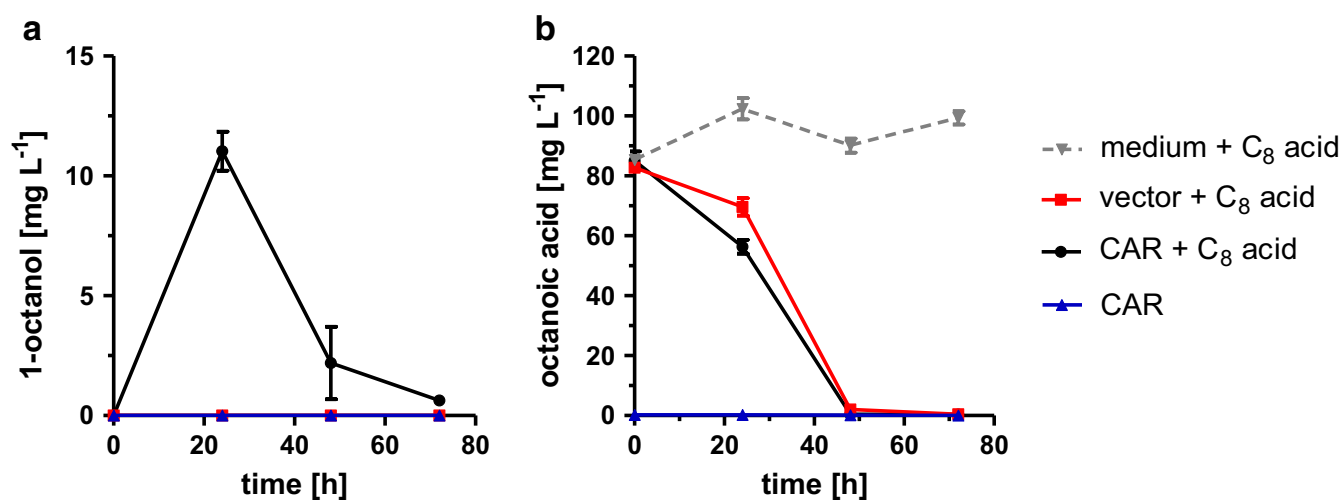

Fig. 5 Uptake and conversion analysis of octanoic acid. a 1-Octanol production and $\mathbf{b}$ octanoic acid consumption of S. cerevisiae BY4741 expressing CAR and Sfp from a multicopy plasmid. Cultivation was performed for $72 \mathrm{~h}$ in buffered YPD medium without and with supplementation of $90 \mathrm{mg} \mathrm{L}^{-1}$ octanoic acid. For reference, noninoculated cultivation medium was treated analogously. Error bars reflect the standard deviations from three biological replicates

decreased in the absence of a CAR (Fig. 5b), indicating alternative reaction pathways for octanoic acid conversion in $S$. cerevisiae. Probably, this is due to degradation of octanoic acid via $\beta$-oxidation in strain BY4741 $[57,60]$. Moreover, the amount of 1-octanol in the extracellular medium also decreased after $24 \mathrm{~h}$ (Fig. 5a). This might be due to its reconversion to octanal by endogenous alcohol dehydrogenases which then might be oxidized, e.g., by the dehydrogenase Hfd1, which has been reported to convert at least long-chain aliphatic aldehydes to carboxylic acids [33].

\section{Overexpression of an aldehyde reductase Ahr from E. coli increases 1-octanol production}

The previous experiment showed that octanoic acid can freely diffuse or is transported in both directions across the yeast plasma membrane, and therefore should not be limiting 1-octanol production. Therefore, we tested octanal reduction as a limiting factor in 1-octanol production. For this reaction, $S$. cerevisiae contains various endogenous ADHs/ALRs, successfully employed for the aldehyde-alcohol conversion in the $\mathrm{C}_{8}-\mathrm{C}_{18}$ range already earlier [29]. However, little is known about the efficiencies of these enzymes to short/medium-chain fatty aldehydes, especially to octanal. It has been shown by Akhtar et al. [31] that the aldehyde reductase Ahr from E. coli accepts a broad range of aliphatic aldehydes $\left(C_{4}\right.$ to $\left.C_{16}\right)$. We overexpressed Ahr from E. coli under the control of the $H X T 7^{-1-392}$ promotor fragment from a high-copy plasmid together with the plasmid encoding for CAR and Sfp in strain RPY21/FAS ${ }^{\mathrm{R} 1834 \mathrm{~K}}$ under aerobic conditions. Overexpression of Ahr led to a twofold increase in the absolute 1 -octanol titer $\left(49.5 \pm 0.8 \mathrm{mg} \mathrm{L}^{-1}\right.$ after $72 \mathrm{~h}$ ) in the extracellular medium (Fig. 6a). This increase in 1-octanol production is also reflected in a decreased maximal optical density of the cell culture after $72 \mathrm{~h}$ compared to the control strain without Ahr (Fig. 6b), probably due to the negative effect of 1-octanol on cell growth (Fig. 4a). When the 1-octanol titers are normalized to the final $\mathrm{OD}_{600}$ of the cultures, overexpression of Ahr resulted in a threefold increase of 1-octanol $\left(7.9 \pm 0.4 \mathrm{mg} \mathrm{L}^{-1} \mathrm{OD}_{600}^{-1}\right.$ compared to $2.8 \pm 0.3 \mathrm{mg} \mathrm{L}^{-1}$ $\mathrm{OD}_{600}^{-1}$ after $72 \mathrm{~h}$ ). Furthermore, the presence of Ahr nearly completely prevented the accumulation of octanoic acid $\left(0.6 \pm 0.0 \mathrm{mg} \mathrm{L}{ }^{-1}\right.$ after $\left.72 \mathrm{~h}\right)$ compared to the strain without Ahr $\left(113.2 \pm 2.6 \mathrm{mg} \mathrm{L}^{-1}\right)$ (Fig. 6c). This result revealed that the reduction of octanal to 1-octanol by endogenous ADHs and ALRs was a limiting step in the original pathway.

\section{In situ extraction of 1-octanol}

Since already minor concentrations of 1-octanol inhibited growth of the yeast cells (Fig. 4a), which makes further improvements toward higher 1-octanol titers difficult, one possibility to circumvent this problem could be an in situ extraction of released 1-octanol in a two-phase fermentation using an organic solvent as the secondary phase. An appropriate solvent is dodecane which was shown to have no negative effects on yeast growth (Fig. 7) [61, 62] and was already used for production of long-chain fatty alcohols [22, 24]. To test if dodecane as secondary phase can improve growth in the presence of 1-octanol by trapping it out of the yeast culture, different concentrations of 1-octanol were added to yeast cultures of the wild-type strain BY4741 overlaid with $20 \%$ dodecane, and growth curves were determined (Fig. 7). Indeed, this time, the addition of even $150 \mathrm{mg} \mathrm{L}^{-1} 1$-octanol to the yeast culture with 

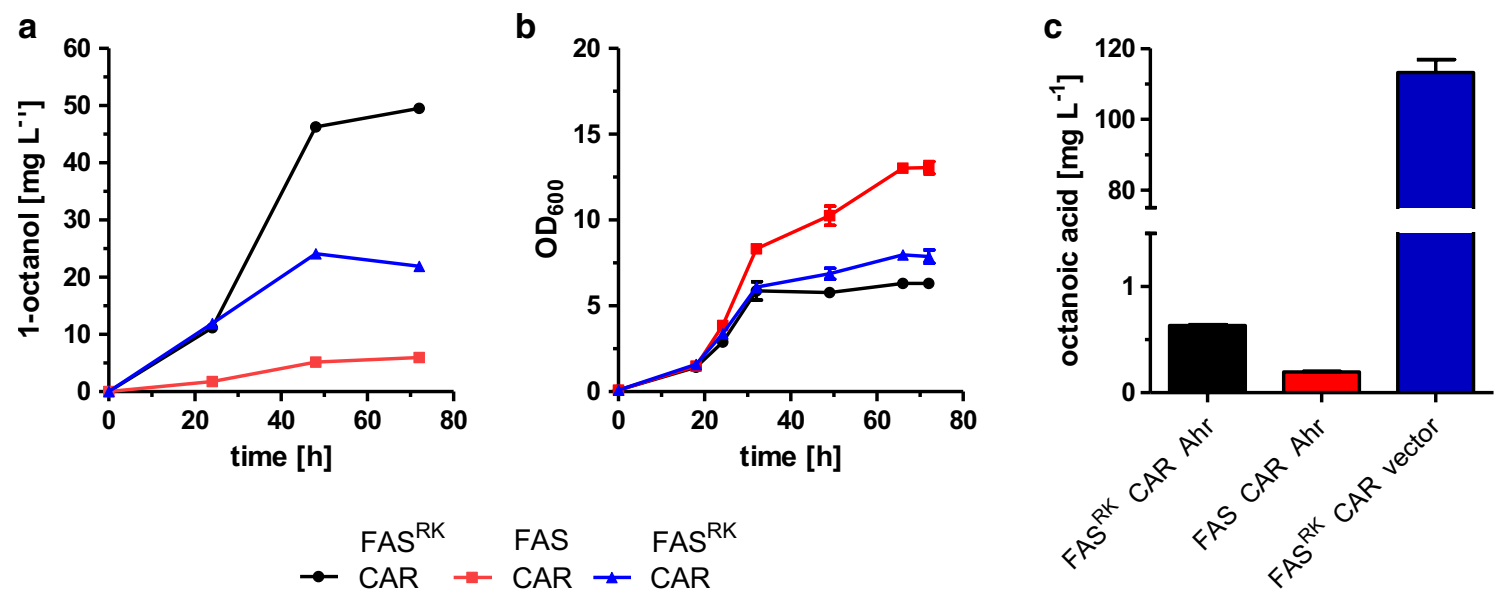

Fig. 6 Increase in 1-octanol production in a yeast strain by additional overexpression of heterologous Ahr. Strain RPY21/FAS ${ }^{\text {R1834K }}$ expressing CAR and Sfp together with Ahr from E. coli from a high-copy plasmid (black), was grown for $72 \mathrm{~h}$ in buffered YPD medium. For comparison, analogous combinations of wild-type FAS with CAR, Sfp, and Ahr (red) as well as mutated FAS R1834K with empty vector instead of Ahr are shown (blue). Error bars indicate the standard deviation from three biological replicates. $\mathbf{a} \mathrm{OD}_{600}$ and 1 -octanol $\mathbf{b}$ were analyzed at different time points. $\mathbf{c}$ Final octanoic acid concentration after $72 \mathrm{~h}$. FAS ${ }^{\mathrm{RK}}$ means FAS ${ }^{\mathrm{R} 1834 \mathrm{~K}}$

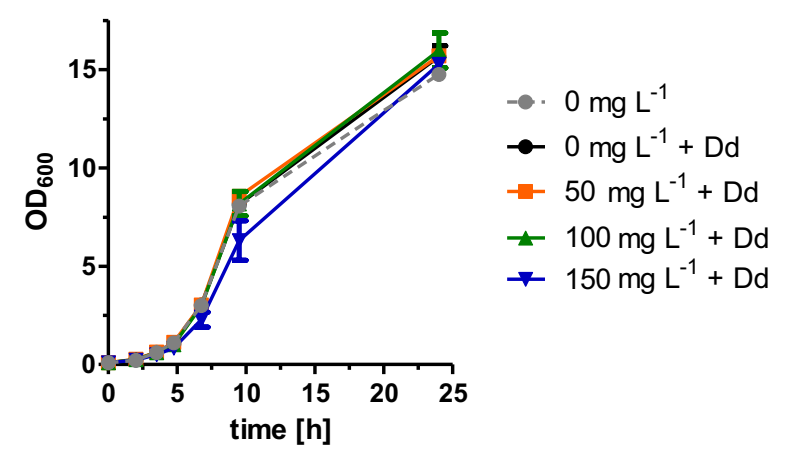

Fig. 7 Growth behavior of strain BY4741 in the presence of 20\% dodecane and different 1-octanol concentrations. BY4741 was cultivated up to $24 \mathrm{~h}$ in buffered YPD medium overlaid with 20\% dodecane (Dd) and supplemented with different 1-octanol concentrations. For comparison, also the growth curve of a culture without dodecane was determined (gray). Error bars reflect the standard deviations from two biological replicates. $\mathrm{OD}_{600}$ was analyzed at different time points

$20 \%$ dodecane did not affect growth. Based on these results, a two-phase fermentation with the 1-octanol producing strain was performed using dodecane as a secondary phase for in situ extraction. To achieve this, we overexpressed Ahr, CAR, and Sfp from highcopy plasmids in strain RPY21/FAS ${ }^{\mathrm{R} 1834 \mathrm{~K}}$ under aerobic conditions in buffered media overlaid with and without $20 \%$ of dodecane. After $72 \mathrm{~h}$, the growth was determined by $\mathrm{OD}_{600}$ measurements, and the amounts of fatty acids and fatty alcohols in the aqueous and in the dodecane phase were analyzed. We found that in the two-phase fermentation, no 1-octanol was detectable in the aqueous phase revealing the efficient extraction of 1-octanol. However, analysis of 1-octanol in the dodecane layer showed that 1-octanol production was reduced by about $25 \%$ compared to the strain cultivated without dodecane (Fig. 8a) (it should be noted that the concentration of 1-octanol determined in the dodecane phase was calculated on the volume of the aqueous phase of the culture). This is likely due to the sequestration of octanoic acid into the dodecane phase (Fig. 8a). Cultivation of the strain RPY21/FAS ${ }^{\mathrm{R} 1834 \mathrm{~K}}$ without the 1-octanol pathway (which yields higher titers of octanoic acid) in buffered medium overlaid with $20 \%$ dodecane confirmed the partial accumulation of octanoic acid in the organic phase (Fig. 8b). Although addition of dodecane could circumvent the inhibitory effect of added 1-octanol on growth (Fig. 7), surprisingly, this was not the case when 1-octanol was produced by the cells themselves (Fig. 8a). Here, the growth of the 1-octanol producing yeast cultures with dodecane was only slightly improved. Taken together, in situ extraction could not improve 1-octanol production and the speedup of the downstream pathway for octanoic acid production is necessary to compensate the loss of octanoic acid into the organic layer. The results also suggest that beside the toxic effect of 1-octanol, its production somehow also inhibits growth of the cells which might partially be connected to a limited supply of ATP and the cofactor NADPH required for octanoic acid production as well as for the CAR and Ahr reactions. 


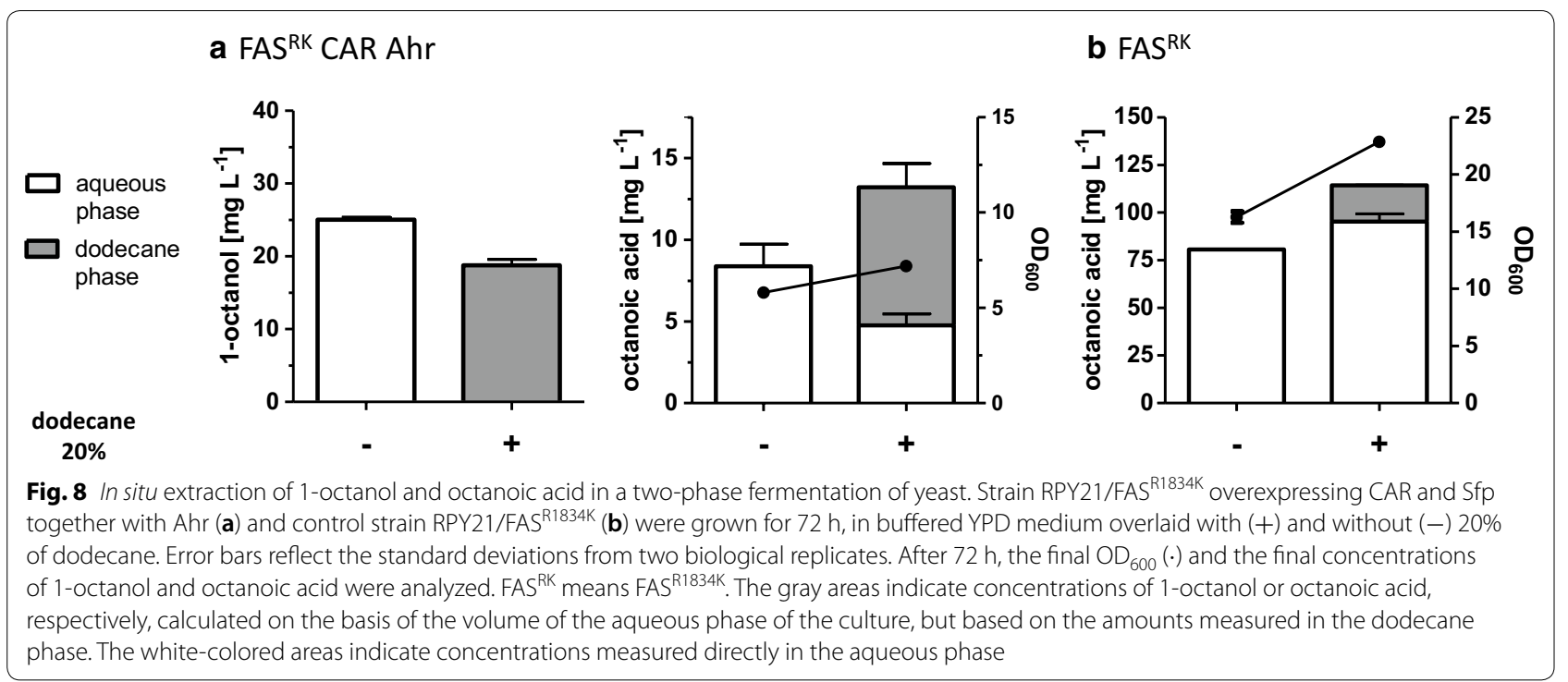

\section{Conclusion}

This is the first study to report on dedicated production of 1-octanol in $S$. cerevisiae. We achieved the nearly selective production of 1-octanol in $S$. cerevisiae by combining a proprietary $\mathrm{C}_{8}$-acid producing FAS ${ }^{\mathrm{R} 1834 \mathrm{~K}}$-mutant with a two-step reduction pathway composed of CAR, Sfp, and Ahr $[14,53]$. In the process of the current study, the chain length specificity of the carbon chain-providing FAS is the decisive step to ensure specific 1-octanol production. Nevertheless, toxicity of 1-octanol and a negative effect of its production on growth of the cells pose fresh challenges for further optimizations.

\section{Methods}

\section{Yeast strain, media, and transformation}

The haploid S. cerevisiae strain RPY21 used in this study for fatty alcohol production has a BY background and is based on BY.PK1238_1A_KO with knocked out FAS1 and FAS2 from previous studies [53]. The deletion of the fatty acyl-CoA synthetase $\Delta f a a 2$ was generated using the CRISPR-Cas9 system [63]. The relevant genotype of RPY21 is Mato; ura $3 \Delta 0$; his $3 \Delta 0$; leu $2 \Delta 0$; TRP1; lys2A0; MET15; fas1::uptag-kanMX4-downtag; fas2::uptag-kanMX4-downtag; $\triangle$ faa2. RPY21 was transformed as described in Gajewski et al. [53]. Selection of yeast transformants was done on the defined synthetic complete media (SCD) as described in Bruder et al. [64] without leucine and histidine containing the respective antibiotics $\left(200 \mu \mathrm{g} \mathrm{mL}^{-1}\right.$ hygromycin; $100 \mu \mathrm{g} \mathrm{mL}^{-1}$ nourseothricin sulfate). The strain BY4741 and the strain CEN.PK2-1C for plasmid construction by homologous recombination were transformed according to protocols by Gietz and Schiestl [65].

\section{Growth experiments}

The strain BY4741 was pregrown in YPD medium buffered with $100 \mathrm{mM}$ potassium phosphate and adjusted to a pH of 6.5 as described in Gajewski et al. [53] without supplementation of free FAs. After washing steps, the main culture $(50 \mathrm{~mL}$ YPD in $300 \mathrm{~mL}$ flasks; two biological replicates) was inoculated to $\mathrm{OD}_{600}=0.1$, supplemented with different concentrations of 1-octanol $(0,50,100$, and $\left.150 \mathrm{mg} \mathrm{L}^{-1}\right)$, octanal $\left(0,50,100\right.$, and $\left.150 \mathrm{mg} \mathrm{L}^{-1}\right)$, or octanoic acid $\left(0,100,200\right.$, and $\left.400 \mathrm{mg} \mathrm{L}^{-1}\right)$ and aerobically shaken for $24 \mathrm{~h}$ at 180 r.p.m. at $30{ }^{\circ} \mathrm{C}$. $\mathrm{OD}_{600}$ was analyzed at different time points.

\section{S. cerevisiae fermentations}

Saccharomyces cerevisiae strains were cultured in YPD medium as described in Gajewski et al. [53] without supplementation of free FAs. The medium was additionally buffered with $100 \mathrm{mM}$ potassium phosphate and adjusted to a $\mathrm{pH}$ of 6.5 . To test the 1-octanol production of the different strains, a preculture was inoculated in buffered YPD medium and grown aerobically to exponential phase. After washing steps, the main culture $(50 \mathrm{~mL}$ YPD with respective antibiotics; two to three biological replicates) was inoculated to $\mathrm{OD}_{600}=0.1$ and aerobically shaken for $72 \mathrm{~h}$ at 180 r.p.m. and $30{ }^{\circ} \mathrm{C}$.

For the in situ extraction, the main culture $(25 \mathrm{~mL}$ YPD with respective antibiotics; two biological replicates) was inoculated to $\mathrm{OD}_{600}=0.1$ and overlaid with $20 \%$ dodecane $(5 \mathrm{~mL})$. Fatty alcohols, fatty acids, and $\mathrm{OD}_{600}$ were analyzed at different time points. The final 1-octanol 
concentration after $72 \mathrm{~h}$ was normalized to the final $\mathrm{OD}_{600}$ value $\left(\mathrm{mg} \mathrm{L}^{-1} \mathrm{OD}_{600}\right)$.

\section{Plasmid and strain construction}

The plasmids used in this study are listed in Table 1. FASrelated plasmids are described in Gawjeski et al. [53]. Genes encoding carboxylic acid reductase CAR from $M$. marinum (UniProt: B2HN69) and the phosphopantetheinyl transferase Sfp from B. subtilis (UniProt: P39135) were codon-optimized according to the yeast glycolytic codon usage [66]. The plasmid pRS62H-CAR-Sfp was assembled by homologous recombination in yeast with

Table 1 List of plasmids used in this study

\begin{tabular}{|c|c|c|}
\hline Plasmid name & Description & References \\
\hline pRS315-FAS1-Wt & $\begin{array}{l}\text { CENGARS4, AmpR, LEU2, } p_{\text {FASI }}{ }^{S C} \text { FAS1-Wt- } \\
t_{\text {FAS1 }}\end{array}$ & [53] \\
\hline pRS315-FAS1-RK & 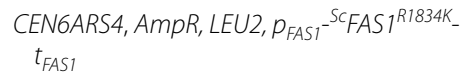 & [53] \\
\hline pRS313-FAS2-Wt & $\begin{array}{l}\text { CENGARS4, AmpR, HIS3, } p_{\text {FAS2 }}{ }^{-{ }^{S C} F A S 2-W t-} \\
t_{\text {FAS2 }}\end{array}$ & [53] \\
\hline pRS62H & $\begin{array}{l}2 \mu, \text { hphNT1, AmpR, truncated HXT7 pro- } \\
\text { motor }\left(\mathrm{p}_{\mathrm{HXT}}^{-1-392)} \text { ) and } F B A 1 \text { terminator }\right.\end{array}$ & {$[68]$} \\
\hline pRS62 N & $\begin{array}{l}2 \mu \text {, natNT2, AmpR, shortened HXT7 pro- } \\
\text { motor ( } \text { p }_{\text {HXT7 }}^{-1-392} \text { ) and CYC1 terminator }\end{array}$ & {$[68]$} \\
\hline pRS62H-CAR-Sfp & $\begin{array}{l}\mathrm{pRS62H} ; p_{H X T 7}^{-1-392{ }_{-} M m} C A R-t_{F B A i} ; p_{P G K 1}{ }^{B S} S f p- \\
t_{P G M 2}\end{array}$ & This study \\
\hline pRS62 N-Ahr & pRS62N; $p_{H X T 7}^{-1-392-E C} A h r-t_{C Y C 1}$ & This study \\
\hline
\end{tabular}

Genes from Saccharomyces cerevisiae (Sc), Mycobacterium marinum (Mm), E. coli $(E c)$, and Bacillus subtilis $(B s)$ are indicated by prefixes in superscript. $h p h N T 1$ hygromycin resistance, Amp ampicillin resistance, natNT2 nourseothricin sulfate resistance four PCR fragments with 30 bp overlaps. Yeast was transformed as described above with a mixture of these fragments generated by PCR using primers shown in Table 2 . The assembled plasmids were recovered by yeast DNA preparations and transformed into $E$. coli for amplification by standard procedures. The construction of the plasmid pRS62N-Ahr was performed by Gibson assembly as described in Gibson et al. [67]. The bacterial gene $A h r$ [previously known as yigB (UniProt: P27250)] was amplified from chromosomal DNA of $E$. coli DH $5 \alpha$ using primers shown in Table 2.

\section{Fatty alcohol extraction}

For the extraction of fatty alcohols from the culture medium, the cells were separated from the medium (8000 rcf, $3 \mathrm{~min}$ ). $500 \mu \mathrm{L}$ supernatant was mixed with $1 \mathrm{~mL}$ ethyl acetate containing $50 \mathrm{mg} \mathrm{L}{ }^{-1}$ heptanol as internal standard and thoroughly shaken. After centrifugation (5000 rcf, $2 \mathrm{~min}$ ), $500 \mu \mathrm{L}$ of the organic phase was transferred to a gas chromatography (GC) vial. For the determination of the amount of fatty alcohols in the dodecane layer, $100 \mu \mathrm{L}$ of the dodecane overlay was mixed with $900 \mu \mathrm{L}$ ethyl acetate containing $50 \mathrm{mg} \mathrm{L}^{-1}$ heptanol as internal standard in a $\mathrm{GC}$ vial.

\section{Fatty acid extraction and derivatization}

For the extraction of free fatty acids present in the culture medium, the cells were separated from the medium (3500 rcf, $10 \mathrm{~min}$ ). An internal standard (0.2 mg heptanoic acid) was added to $10 \mathrm{~mL}$ supernatant and mixed with $1 \mathrm{~mL} 1 \mathrm{M} \mathrm{HCl}$ and $2.5 \mathrm{~mL}$ methanol-chloroform solution (1:1). The solution was vigorously shaken (5 min)

Table 2 Relevant primers for plasmid construction

\begin{tabular}{|c|c|c|}
\hline Primer name & Sequence $5^{\prime}-3^{\prime}$ & Amplicon \\
\hline SHP35_pPGK1_for & $\begin{array}{l}\text { AACCCTGGCGTTACCCAACTTAATCGCCTTGCAG } \\
\text { CATGTTTGCAAAAAGAACAAAACTG }\end{array}$ & PGK1 promotor \\
\hline CBP160_pPGK1_rev & TGTTTTATATTTGTTGTAAAAAGTAGATAATTAC & PGK1 promotor \\
\hline CBP35_tPGM2_for & AACGAATGATTTACTAATGGC & PGM2 terminator \\
\hline SHP36_tPGM2_rev & $\begin{array}{l}\text { GAAATCGGCAAAATCCCTTATAAATCAAAAGAAT } \\
\text { AGACAAAAAACTCGGGGTAGGTAAT }\end{array}$ & PGM2 terminator \\
\hline SHP54_Ahr_for & $\begin{array}{l}\text { CAAAAACAAAAAGTTTTTTTAATTTTAATCAAAAA } \\
\text { ATGTCGATGATAAAAAGCTATGCC }\end{array}$ & Ahr ORF \\
\hline SHP53_Ahr_rev & $\begin{array}{l}\text { ATGTAAGCGTGACATAACTAATTACATGACTCGA } \\
\text { GTCAAAAATCGGCTTTCAACAC }\end{array}$ & Ahr ORF \\
\hline DR_Faa2 & $\begin{array}{l}\text { GGAAGAATGCAGGTTACAAAAAACGGATAAGAA } \\
\text { CAAACTTGTTTCGAAATGTACTTATGACGATTTGG } \\
\text { AACACATTCAAACTAGAAAAAACTTTGATGTA }\end{array}$ & $\begin{array}{l}\text { Donor-DNA fragment for FAA2 } \\
\text { deletion }\end{array}$ \\
\hline CC_FAA2-rev & $\begin{array}{l}\text { CGTAAGGTTTCAAAATCTTCGATCATTTATCTTTC } \\
\text { ACTGCGGAG }\end{array}$ & $\begin{array}{l}\text { Amplification of a CRISPR-Cas9 } \\
\text { plasmid pRCCN for deletion of FAA2, reverse }\end{array}$ \\
\hline CC_FAA2-fW & $\begin{array}{l}\text { GAAGATTTTGAAACCTTACGGTTTTAGAGCTAGAA } \\
\text { ATAGCAAGTTAAAATAAGG }\end{array}$ & $\begin{array}{l}\text { Amplification of a CRISPR-Cas9 } \\
\text { plasmid pRCCN for deletion of FAA2, forward }\end{array}$ \\
\hline
\end{tabular}

The abbreviations within the primer names were used as follows: forward primer ( $\mathrm{fw}$ ) and reverse primer (rev) 
and then centrifuged for $10 \mathrm{~min}$ at $3.000 \mathrm{rcf}$. The chloroform layer was recovered and evaporated overnight. The methylation of the fatty acids was performed as described in Ichihara and Fukubayashi [69]. The samples were dissolved in $200 \mu \mathrm{L}$ of toluene, mixed with $1.5 \mathrm{~mL}$ of methanol and $300 \mu \mathrm{L}$ of $8.0 \%(\mathrm{w} / \mathrm{v}) \mathrm{HCl}$ solution [conc. $\mathrm{HCl}$ $(35 \% \mathrm{w} / \mathrm{w}$; $9.7 \mathrm{~mL})$ was diluted with $41.5 \mathrm{~mL}$ of methanol], vortexed vigorously, and incubated at $100{ }^{\circ} \mathrm{C}$ for $3 \mathrm{~h}$ to form fatty acid methyl ester (FAME). After cooling under ice for $10 \mathrm{~min}, 1 \mathrm{~mL} \mathrm{H}_{2} \mathrm{O}$ and $1 \mathrm{~mL}$ hexane were added to the sample. The mixture was shaken thoroughly, and the organic phase was transferred to a GC vial.

For the derivatization of the fatty acids from the in situ extraction experiment, the derivative reagent Bis(trimethylsilyl)-trifluoroacetamide (BSTFA) was used. After separation of the cells from the medium (3500 rcf, $10 \mathrm{~min}$ ), $50 \mu \mathrm{L} 1 \mathrm{M} \mathrm{HCl}$ and $0.01 \mathrm{mg}$ heptanoic acid as an internal standard were added to $500 \mu \mathrm{L}$ supernatant and mixed with $1 \mathrm{~mL}$ ethyl acetate. The ethyl acetate layer was evaporated overnight, and the samples were dissolved in $100 \mu \mathrm{L}$ ethyl acetate and mixed with $100 \mu \mathrm{L}$ BSTFA. For the determination of the amount of fatty acids in the dodecane layer, $20 \mu \mathrm{L}$ of the dodecane layer was mixed with $80 \mu \mathrm{L}$ ethyl acetate, $0.01 \mathrm{mg}$ of heptanoic acid as an internal standard, and $100 \mu \mathrm{L}$ BSTFA. The derivatization was done for $45 \mathrm{~min}$ at $80{ }^{\circ} \mathrm{C}$. After cooling at $4{ }^{\circ} \mathrm{C}$ for $15 \mathrm{~min}$, the samples were analyzed by GC.

\section{GC-FID analysis of FAMEs and fatty alcohols}

The gas chromatographic measurements were carried out on a Perkin Elmer Clarus 400 system (Perkin Elmer, Germany) equipped with an Elite FFAP capillary column $(30 \mathrm{~m} \times 0.25 \mathrm{~mm}$, film thickness: $0.25 \mu \mathrm{m}$; PerkinElmer, Germany) and a flame ionization detector (Perkin Elmer, Germany). $1 \mu \mathrm{L}$ of the sample was analyzed after split injection (1:10); helium was used as carrier gas (90 kPa). For fatty acid methyl ester (FAME) quantification, the temperatures of the injector and detector were 200 and $250{ }^{\circ} \mathrm{C}$, respectively. The following temperature program was applied: heating to $50{ }^{\circ} \mathrm{C}$ for $5 \mathrm{~min}$; increase of $10{ }^{\circ} \mathrm{C} \mathrm{min}{ }^{-1}$ to $120{ }^{\circ} \mathrm{C}$ and hold for $5 \mathrm{~min}$; increase at the rate of $15{ }^{\circ} \mathrm{C} \mathrm{min}{ }^{-1}$ to $180{ }^{\circ} \mathrm{C}$ and hold for $10 \mathrm{~min}$; increase at the rate of $20^{\circ} \mathrm{C} \mathrm{min}{ }^{-1}$ to $220^{\circ} \mathrm{C}$, and hold for 7 min. FAME were identified and quantified by comparison with authentic standard substances. For fatty alcohol quantification, an initial temperature of $50{ }^{\circ} \mathrm{C}$ was maintained for $5 \mathrm{~min}$, followed by an increase at the rate of $20{ }^{\circ} \mathrm{C} \min ^{-1}$ to $210{ }^{\circ} \mathrm{C}$ and kept constant for $5 \mathrm{~min}$. After a further increase at the rate of $20{ }^{\circ} \mathrm{C} \mathrm{min}-1$ to $230{ }^{\circ} \mathrm{C}$, the temperature was kept constant for $6 \mathrm{~min}$. The temperatures of both the injector and detector were $250{ }^{\circ} \mathrm{C}$. Fatty alcohols were identified and quantified by comparison with authentic standard substances. For the in situ extraction experiment with dodecane as second phase, the column Elite $5 \mathrm{MS}$ capillary column $(30 \mathrm{~m} \times 0.25 \mathrm{~mm}$, film thickness $1.00 \mu \mathrm{m}$, Perkin Elmer, Germany) was used for analysis of FAMEs and fatty alcohols. The temperatures of the injector and detector were 250 and $300{ }^{\circ} \mathrm{C}$, respectively. The following temperature program was applied for FAMEs: $50{ }^{\circ} \mathrm{C}$ for $5 \mathrm{~min}$, increase at the rate of $10{ }^{\circ} \mathrm{C} \mathrm{min}{ }^{-1}$ to $120^{\circ} \mathrm{C}$ and hold for $5 \mathrm{~min}$; increase at the rate of $15{ }^{\circ} \mathrm{C} \mathrm{min}{ }^{-1}$ to $220{ }^{\circ} \mathrm{C}$, and hold for $10 \mathrm{~min}$, increase at the rate of $20^{\circ} \mathrm{C} \mathrm{min}-1$ to $300^{\circ} \mathrm{C}$, and hold for $5 \mathrm{~min}$. For fatty alcohols, the following temperature program was applied: $50{ }^{\circ} \mathrm{C}$ for $5 \mathrm{~min}$, increase at the rate of $20{ }^{\circ} \mathrm{C} \mathrm{min}{ }^{-1}$ to $220^{\circ} \mathrm{C}$ and hold for $2 \mathrm{~min}$; increase at the rate of $20^{\circ} \mathrm{C} \mathrm{min}^{-1}$ to $300^{\circ} \mathrm{C}$, and hold for $5 \mathrm{~min}$.

\section{Abbreviations}

$\mathrm{OD}_{600}$ : optical density at $600 \mathrm{~nm}$; PGK1: 3-Phosphoglycerate kinase; HXT7: high-affinity glucose transporter; PGM2: phosphoglucomutase; CYC1: cytochrome c; FBA1: fructose-1,6-bisphosphate aldolase; FAS: fatty acid synthase; FAA2: medium-chain fatty acyl-CoA synthetase; Ahr: aldehyde reductase; CAR: carboxylic acid reductase; ALR: aldehyde reductase; ADH: alcohol dehydrogenase; Sfp: phosphopantetheinyl transferase.

\section{Authors' contributions}

$\mathrm{SH}, \mathrm{MF}, \mathrm{MG}, \mathrm{MO}$, and $\mathrm{EB}$ conceived the study. SH conducted the experiments. $\mathrm{SH}, \mathrm{MO}$, and $\mathrm{EB}$ analyzed the data. $\mathrm{SH}, \mathrm{MF}$, and EB wrote the paper. All authors read and approved the manuscript.

\section{Author details \\ ${ }^{1}$ Faculty of Biological Sciences, Institute of Molecular Bioscience, Goethe University Frankfurt, Max-von-Laue-Str. 9, 60438 Frankfurt, Germany. ${ }^{2}$ Institute of Organic Chemistry and Chemical Biology, Buchmann Institute for Molecu- lar Life Sciences, Cluster of Excellence "Macromolecular Complexes", Goethe University Frankfurt, Max-von-Laue-Str. 15, 60438 Frankfurt, Germany.}

\section{Acknowledgements}

We thank Renata Pavlovic for providing the yeast strain RPY21.

\section{Competing interests}

E.B. and M.G. are inventors of EP patent application No. 15162192.7 filed on April 1, 2015, and of EP patent application No. 15174342.4 filed on June 26, 2015, by Goethe-University Frankfurt, concerning short-chain acyl-CoA producing FAS variants. There are no other competing interests.

\section{Availability of data and materials}

The datasets used and/or analyzed during the current study are available from the corresponding author upon reasonable request.

\section{Consent for publication}

Not applicable.

\section{Ethics approval and consent to participate}

Not applicable.

\section{Funding}

The project underlying this report is financially supported by the German Federal Ministry of Food and Agriculture following a decision of the German Bundestag under the Grant Number 22026315; the responsibility for the content of this publication lies with the authors.

\section{Publisher's Note}

Springer Nature remains neutral with regard to jurisdictional claims in published maps and institutional affiliations. 
Received: 12 December 2017 Accepted: 23 May 2018

Published online: 01 June 2018

\section{References}

1. Chapman L. Transport and climate change: a review. J Transp Geogr. 2007. https://doi.org/10.1016/j.jtrangeo.2006.11.008.

2. Contribution of Working Group III to the Fifth Assessment Report of the Intergovernmental Panel on Climate Change 2014. Climate Change. In: Edenhofer O, Pichs-Madruga R, Sokona Y, Farahani E, Kadner S, Seyboth K, Adler A, Baum I, Brunner S, Eickemeier P, Kriemann B, Savolainen J, Schlömer S, von Stechow C, Zwickel T, Minx JC, editors. Mitigation of climate change. Cambridge: Cambridge University Press; 2014.

3. Peralta-Yahya PP, Zhang F, del Cardayre SB, Keasling JD. Microbial engineering for the production of advanced biofuels. Nature. 2012. https:// doi.org/10.1038/nature11478.

4. Karatzos S, van Dyk JS, McMillan JD, Saddler J. Drop-in biofuel production via conventional (lipid/fatty acid) and advanced (biomass) routes. Part I. Biofuels Bioprod Biorefining. 2017; https://doi.org/10.1002/bbb.1746.

5. Junne S, Kabisch J. Fueling the future with biomass: processes and pathways for a sustainable supply of hydrocarbon fuels and biogas. Eng Life Sci. 2017. https://doi.org/10.1002/elsc.201600112.

6. Yu A-Q, Pratomo Juwono NK, Leong SSJ, Chang MW. Production of fatty acid-derived valuable chemicals in synthetic microbes. Front Bioeng Biotechnol. 2014. https://doi.org/10.3389/fbioe.2014.00078.

7. Kang M-K, Nielsen J. Biobased production of alkanes and alkenes through metabolic engineering of microorganisms. J Ind Microbiol Biotechnol. 2017. https://doi.org/10.1007/s10295-016-1814-y.

8. Cheon S, Kim HM, Gustavsson M, Lee SY. Recent trends in metabolic engineering of microorganisms for the production of advanced biofuels. Curr Opin Chem Biol. 2016. https://doi.org/10.1016/j.cbpa.2016.08.003.

9. Zargar A, Bailey CB, Haushalter RW, Eiben CB, Katz L, Keasling JD. Leveraging microbial biosynthetic pathways for the generation of 'drop-in' biofuels. Curr Opin Biotechnol. 2017. https://doi.org/10.1016/j.copbi 0.2017.03.004.

10. Kremer F, Blank LM, Jones PR, Akhtar MK. A comparison of the microbial production and combustion characteristics of three alcohol biofuels: ethanol, 1-butanol, and 1-octanol. Front Bioeng Biotechnol. 2015. https:// doi.org/10.3389/fbioe.2015.00112

11. Kerschgens B, Cai L, Pitsch H, Heuser B, Pischinger S. Di- $n$-buthylether, $n$-octanol, and $n$-octane as fuel candidates for diesel engine combustion. Combust Flame. 2016. https://doi.org/10.1016/j.combustfla me.2015.09.001.

12. Rajesh Kumar B, Saravanan S, Rana D, Nagendran A. A comparative analysis on combustion and emissions of some next generation higheralcohol/diesel blends in a direct-injection diesel engine. Energy Convers Manag. 2016. https://doi.org/10.1016/j.enconman.2016.04.053.

13. Cai L, Uygun Y, Togbé $C$, Pitsch H, Olivier H, Dagaut P, Sarathy SM. An experimental and modeling study of $n$-octanol combustion. Proc Combust Inst. 2015. https://doi.org/10.1016/j.proci.2014.05.088.

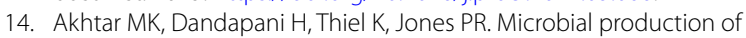
1-octanol: a naturally excreted biofuel with diesel-like properties. Metab Eng Commun. 2015. https://doi.org/10.1016/j.meteno.2014.11.001.

15. Atsumi S, Hanai T, Liao JC. Non-fermentative pathways for synthesis of branched-chain higher alcohols as biofuels. Nature. 2008. https://doi. org/10.1038/nature06450

16. Zhang K, Sawaya MR, Eisenberg DS, Liao JC. Expanding metabolism for biosynthesis of nonnatural alcohols. Proc Natl Acad Sci USA. 2008. https ://doi.org/10.1073/pnas.0807157106.

17. Dekishima Y, Lan El, Shen CR, Cho KM, Liao JC. Extending carbon chain length of 1-butanol pathway for 1-hexanol synthesis from glucose by engineered Escherichia coli. J Am Chem Soc. 2011. https://doi. org/10.1021/ja203814d

18. Dellomonaco C, Clomburg JM, Miller EN, Gonzalez R. Engineered reversal of the $\beta$-oxidation cycle for the synthesis of fuels and chemicals. Nature. 2011. https://doi.org/10.1038/nature10333.

19. Wahlen BD, Oswald WS, Seefeldt LC, Barney BM. Purification, characterization, and potential bacterial wax production role of an NADPH-dependent fatty aldehyde reductase from Marinobacter aquaeolei VT8. Appl Environ Microbiol. 2009. https://doi.org/10.1128/AEM.02578-08.
20. Willis RM, Wahlen BD, Seefeldt LC, Barney BM. Characterization of a fatty acyl-CoA reductase from Marinobacter aquaeolei VT8: a bacterial enzyme catalyzing the reduction of fatty acyl-CoA to fatty alcohol. Biochemistry. 2011. https://doi.org/10.1021/bi2008646.

21. Rowland O, Domergue F. Plant fatty acyl reductases: enzymes generating fatty alcohols for protective layers with potential for industrial applications. Plant Sci. 2012. https://doi.org/10.1016/.jplantsci.2012.05.002.

22. d'Espaux L, Ghosh A, Runguphan W, Wehrs M, Xu F, Konzock O, et al. Engineering high-level production of fatty alcohols by Saccharomyces cerevisiae from lignocellulosic feedstocks. Metab Eng. 2017. https://doi. org/10.1016/j.ymben.2017.06.004.

23. Haushalter RW, Groff D, Deutsch S, The L, Chavkin TA, Brunner SF, et al. Development of an orthogonal fatty acid biosynthesis system in E. coli for oleochemical production. Metab Eng. 2015. https://doi.org/10.1016/j. ymben.2015.04.003.

24. Runguphan W, Keasling JD. Metabolic engineering of Saccharomyces cerevisiae for production of fatty acid-derived biofuels and chemicals. Metab Eng. 2014. https://doi.org/10.1016/j.ymben.2013.07.003.

25. Fillet S, Gibert J, Suárez B, Lara A, Ronchel C, Adrio JL. Fatty alcohols production by oleaginous yeast. J Ind Microbiol Biotechnol. 2015. https:// doi.org/10.1007/s10295-015-1674-X.

26. Feng X, Lian J, Zhao H. Metabolic engineering of Saccharomyces cerevisiae to improve 1-hexadecanol production. Metab Eng. 2015. https://doi. org/10.1016/j.ymben.2014.10.001.

27. Hofvander P, Doan TTP, Hamberg M. A prokaryotic acyl-CoA reductase performing reduction of fatty acyl-CoA to fatty alcohol. FEBS Lett. 2011. https://doi.org/10.1016/j.febslet.2011.10.016.

28. Foo JL, Susanto AV, Keasling JD, Leong SSJ, Chang MW. Whole-cell biocatalytic and de novo production of alkanes from free fatty acids in Saccharomyces cerevisiae. Biotechnol Bioeng. 2017. https://doi.org/10.1002/ bit.25920.

29. Tang X, Feng L, Chen L, Chen WN. Engineering Saccharomyces cerevisiae for efficient biosynthesis of fatty alcohols based on enhanced supply of free fatty acids. ACS Omega. 2017. https://doi.org/10.1021/acsom ega.7b00065

30. Zhou YJ, Buijs NA, Zhu Z, Qin J, Siewers V, Nielsen J. Production of fatty acid-derived oleochemicals and biofuels by synthetic yeast cell factories. Nat Commun. 2016. https://doi.org/10.1038/ncomms11709.

31. Akhtar MK, Turner NJ, Jones PR. Carboxylic acid reductase is a versatile enzyme for the conversion of fatty acids into fuels and chemical commodities. Proc Natl Acad Sci USA. 2013. https://doi.org/10.1073/ pnas. 1216516110

32. Venkitasubramanian P, Daniels L, Rosazza JPN. Reduction of carboxylic acids by Nocardia aldehyde oxidoreductase requires a phosphopantetheinylated enzyme. J Biol Chem. 2007. https://doi.org/10.1074/jbc.M6079 80200.

33. Buijs NA, Zhou YJ, Siewers V, Nielsen J. Long-chain alkane production by the yeast Saccharomyces cerevisiae. Biotechnol Bioeng. 2015. https://doi. org/10.1002/bit.25522.

34. Wang $M, W u H, X u J, L i C$, Wang Y, Wang Z. Five fatty acyl-coenzyme A reductases are involved in the biosynthesis of primary alcohols in Aegilops tauschii leaves. Front Plant Sci. 2017. https://doi.org/10.3389/ fpls.2017.01012.

35. Steen EJ, Kang Y, Bokinsky G, Hu Z, Schirmer A, McClure A, et al. Microbial production of fatty-acid-derived fuels and chemicals from plant biomass. Nature. 2010. https://doi.org/10.1038/nature08721.

36. Moura M, Pertusi D, Lenzini S, Bhan N, Broadbelt L, Tyo KEJ. Characterizing and predicting carboxylic acid reductase activity for diversifying bioaldehyde production. Biotechnol Bioeng. 2016. https://doi.org/10.1002/ bit.25860.

37. Finnigan W, Thomas A, Cromar H, Gough B, Snajdrova R, Adams JP, et al. Characterization of carboxylic acid reductases as enzymes in the toolbox for synthetic chemistry. ChemCatChem. 2017. https://doi.org/10.1002/ cctc.201601249.

38. Wang G, Xiong X, Ghogare R, Wang P, Meng Y, Chen S. Exploring fatty alcohol-producing capability of Yarrowia lipolytica. Biotechnol Biofuels. 2016. https://doi.org/10.1186/s13068-016-0512-3.

39. Marcheschi RJ, Li H, Zhang K, Noey EL, Kim S, Chaubey A, et al. A synthetic recursive" +1 " pathway for carbon chain elongation. ACS Chem Biol. 2012. https://doi.org/10.1021/cb200313e. 
40. Machado HB, Dekishima Y, Luo H, Lan El, Liao JC. A selection platform for carbon chain elongation using the CoA-dependent pathway to produce linear higher alcohols. Metab Eng. 2012. https://doi.org/10.1016/j.ymben .2012.07.002.

41. Sheng J, Stevens J, Feng X. Pathway Compartmentalization in peroxisome of Saccharomyces cerevisiae to produce versatile medium chain fatty alcohols. Sci Rep. 2016. https://doi.org/10.1038/srep26884.

42. Gibson BR, Lawrence SJ, Leclaire JPR, Powell CD, Smart KA. Yeast responses to stresses associated with industrial brewery handling. FEMS Microbiol Rev. 2007. https://doi.org/10.1111/j.1574-6976.2007.00076.x

43. Weber C, Farwick A, Benisch F, Brat D, Dietz H, Subtil T, Boles E. Trends and challenges in the microbial production of lignocellulosic bioalcohol fuels. Appl Microbiol Biotechnol. 2010. https://doi.org/10.1007/s0025 3-010-2707-z

44. Li M, Borodina I. Application of synthetic biology for production of chemicals in yeast Saccharomyces cerevisiae. FEMS Yeast Res. 2015. https://doi. org/10.1111/1567-1364.12213.

45. Fernandez-Moya R, Da Silva NA. Engineering Saccharomyces cerevisiae for high-level synthesis of fatty acids and derived products. FEMS Yeast Res. 2017. https://doi.org/10.1093/femsyr/fox071

46. Fischer M, Rhinow D, Zhu Z, Mills DJ, Zhao ZK, Vonck J, Grininger M. CryoEM structure of fatty acid synthase (FAS) from Rhodosporidium toruloides provides insights into the evolutionary development of fungal FAS. Protein Sci. 2015. https://doi.org/10.1002/pro.2678.

47. Jenni S, Leibundgut M, Boehringer D, Frick C, Mikolásek B, Ban N. Structure of fungal fatty acid synthase and implications for iterative substrate shuttling. Science. 2007. https://doi.org/10.1126/science.1138248.

48. Johansson P, Mulinacci B, Koestler C, Vollrath R, Oesterhelt D, Grininger M. Multimeric options for the auto-activation of the Saccharomyces cerevisiae FAS type I megasynthase. Structure. 2009. https://doi.org/10.1016/j. str.2009.06.014.

49. Leibundgut M, Jenni S, Frick C, Ban N. Structural basis for substrate delivery by acyl carrier protein in the yeast fatty acid synthase. Science. 2007. https://doi.org/10.1126/science.1138249.

50. Lomakin IB, Xiong Y, Steitz TA. The crystal structure of yeast fatty acid synthase, a cellular machine with eight active sites working together. Cell. 2007. https://doi.org/10.1016/j.cell.2007.03.013.

51. Leber C, Da Silva NA. Engineering of Saccharomyces cerevisiae for the synthesis of short chain fatty acids. Biotechnol Bioeng. 2014. https://doi. org/10.1002/bit.25021.

52. Zhu Z, Zhou YJ, Krivoruchko A, Grininger M, Zhao ZK, Nielsen J. Expanding the product portfolio of fungal type I fatty acid synthases. Nat Chem Biol. 2017. https://doi.org/10.1038/nchembio.2301.

53. Gajewski J, Pavlovic R, Fischer M, Boles E, Grininger M. Engineering fungal de novo fatty acid synthesis for short chain fatty acid production. Nat Commun. 2017. https://doi.org/10.1038/ncomms14650.

54. Gajewski J, Buelens F, Serdjukow S, Janßen M, Cortina N, Grubmüller H, Grininger M. Engineering fatty acid synthases for directed polyketide production. Nat Chem Biol. 2017. https://doi.org/10.1038/nchembio.2314.

55. Xu P, Qiao K, Ahn WS, Stephanopoulos G. Engineering Yarrowia lipolytica as a platform for synthesis of drop-in transportation fuels and oleochemicals. Proc Natl Acad Sci USA. 2016. https://doi.org/10.1073/ pnas. 1607295113

56. Rigouin C, Gueroult M, Croux C, Dubois G, Borsenberger V, Barbe S, et al. Production of medium chain fatty acids by Yarrowia lipolytica: combining molecular design and TALEN to engineer the fatty acid synthase. ACS Synth Biol. 2017. https://doi.org/10.1021/acssynbio.7b00034.

57. van Roermund CWT, ljlst L, Majczak W, Waterham HR, Folkerts $H$, Wanders RJA, Hellingwerf KJ. Peroxisomal fatty acid uptake mechanism in Saccharomyces cerevisiae. J Biol Chem. 2012. https://doi.org/10.1074/jbc. M111.332833.

58. Leber C, Choi JW, Polson B, Da Silva NA. Disrupted short chain specific $\beta$-oxidation and improved synthase expression increase synthesis of short chain fatty acids in Saccharomyces cerevisiae. Biotechnol Bioeng. 2016. https://doi.org/10.1002/bit.25839.

59. Schonauer MS, Kastaniotis AJ, Kursu VAS, Hiltunen JK, Dieckmann CL. Lipoic acid synthesis and attachment in yeast mitochondria. J Biol Chem. 2009. https://doi.org/10.1074/jbc.M109.015594.

60. Borrull A, López-Martínez G, Poblet M, Cordero-Otero R, Rozès N. New insights into the toxicity mechanism of octanoic and decanoic acids on Saccharomyces cerevisiae. Yeast. 2015. https://doi.org/10.1002/yea.3071.

61. Asadollahi MA, Maury J, Møller K, Nielsen KF, Schalk M, Clark A, Nielsen J. Production of plant sesquiterpenes in Saccharomyces cerevisiae: effect of ERG9 repression on sesquiterpene biosynthesis. Biotechnol Bioeng. 2008. https://doi.org/10.1002/bit.21581.

62. Qun J, Shanjing Y, Lehe M. Tolerance of immobilized baker's yeast in organic solvents. Enzyme Microb Technol. 2002. https://doi.org/10.1016/ S0141-0229(02)00048-0.

63. Generoso WC, Gottardi M, Oreb M, Boles E. Simplified CRISPR-Cas genome editing for Saccharomyces cerevisiae. J Microbiol Methods. 2016. https://doi.org/10.1016/j.mimet.2016.06.020.

64. Bruder S, Reifenrath M, ThomikT, Boles E, Herzog K. Parallelised online biomass monitoring in shake flasks enables efficient strain and carbon source dependent growth characterisation of Saccharomyces cerevisiae. Microb Cell Fact. 2016. https://doi.org/10.1186/s12934-016-0526-3.

65. Gietz RD, Schiestl RH. Frozen competent yeast cells that can be transformed with high efficiency using the LiAc/SS carrier DNA/PEG method. Nat Protoc. 2007. https://doi.org/10.1038/nprot.2007.17.

66. Wiedemann B, Boles E. Codon-optimized bacterial genes improve L-Arabinose fermentation in recombinant Saccharomyces cerevisiae. Appl Environ Microbiol. 2008. https://doi.org/10.1128/AEM.02395-07.

67. Gibson DG, Young L, Chuang R-Y, Venter JC, Hutchison CA, Smith HO. Enzymatic assembly of DNA molecules up to several hundred kilobases. Nat Methods. 2009. https://doi.org/10.1038/NMETH.1318.

68. Farwick A, Bruder S, Schadeweg V, Oreb M, Boles E. Engineering of yeast hexose transporters to transport D-xylose without inhibition by D-glucose. Proc Natl Acad Sci USA. 2014. https://doi.org/10.1073/pnas.1323464111.

69. Ichihara Kl, Fukubayashi Y. Preparation of fatty acid methyl esters for gas-liquid chromatography. J Lipid Res. 2010. https://doi.org/10.1194/jlr. d001065.

\footnotetext{
Ready to submit your research? Choose BMC and benefit from:

- fast, convenient online submission

- thorough peer review by experienced researchers in your field

- rapid publication on acceptance

- support for research data, including large and complex data types

- gold Open Access which fosters wider collaboration and increased citations

- maximum visibility for your research: over 100M website views per year
}

At BMC, research is always in progress.

Learn more biomedcentral.com/submissions 